McCance, R. A., and Widdowson, E. M. (1960). Medical Research Council. Special Report Series, No. 297.

MacKeith, R., and Wood, G. (1971). Infant Feeding and Feeding Difficulties, 4th ed. London, Churchill.

Medical Research Council (1959). Special Report Series, No. 296. London, H.M.S.O

Mullins, A. G. (1958). Archives of Disease in Childhood, 33, 307.

National Research Council Food and Nutrition Board (1964). Recommended Dietary Allowances, 6th edn. Washington D.C., National Academy of Sciences and National Research Council.

Newson, L. J., and Newson, E. (1962). British Medical fournal, 2, 1744.

Paton, D. N., and Findlay, L. (1926). Medical Research Council. Special Report Series, No. 101.
Sackett, W. W. (1956). General Practitioner, 14, 98.

Stearns, G. (1939). Physiological Review, 19, 415.

Taitz, L. S. (1971). British Medical fournal, 1, 315.

Tanner, J. M. (1958). In Modern Trends in Paediatrics, ed. A. Holzel and J. P. M. Tizard, London, Butterworth.

Tanner, J. M., Whitehouse, R. H., and Takaishi, M. (1966). Archives of Disease in Childhood, 41, 454, 613.

Thomson, J. (1955). Archives of Disease in Childhood, 30, 322.

Widdowson, E. M. (1969). Fournal of the Royal College of Physicians of London, 3, 285.

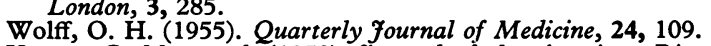

Young, C. M., et al. (1952). Fournal of the American Dietetic Association, 28, 124.

\title{
Significance of milk pH in Newborn Infants
}

\author{
V. C. HARRISON, G. PEAT
}

British Medical fournal, 1972, 4, 515-518

\section{Summary}

Bottle-fed infants do not gain weight as rapidly as breastfed babies during the first week of life. This weight lag can be corrected by the addition of a small amount of alkali (sodium bicarbonate or trometamol) to the feeds. The alkali corrects the acidity of cow's milk which now assumes some of the properties of human breast milk. It has a bacteriostatic effect on specific Escherichia coli in vitro, and in infants it produces a stool with a preponderance of lactobacilli over $E$. coli organisms. When alkali is removed from the milk there is a decrease in the weight of an infant and the stools contain excessive numbers of $E$. coli bacteria.

A pH-corrected milk appears to be more physiological than unaltered cow's milk and may provide some protection against gastroenteritis in early life. Its bacteriostatic effect on specific $E$. coli may be of practical significance in feed preparations where terminal sterilization and refrigeration are not available. The study was conducted during the week after birth, and no conclusions are derived for older infants. The long-term effects of trometamol are unknown. No recommendation can be given for the addition of sodium bicarbonate to milks containing a higher content of sodium.

\section{Introduction}

Cow's milk differs from human milk in many respects. It has a high protein and phosphate content and produces a firm stool with a preponderance of Escherichia coli organisms. Breast milk, with its high lactose, low phosphate, and low protein load, produces a stool with a relatively low $E$. coli count (Bullen and Willis, 1971). In addition, it affords protection against gastroenteritis.

\footnotetext{
Departments of Paediatrics and Child Health and Chemical Pathology, University of Cape Town, South Africa

V. C. HARRISON, M.D., Paediatrician

G. PEAT, DIP.MED.TECH., Senior Technologist
}

A consistent difference has been noted in the weight patterns of normal full-term breast-fed and bottle-fed infants at Mowbray Maternity Hospital, Cape Town. Breast-fed babies regain birth weight a day earlier than bottle-fed infants despite their larger initial weight loss (Table I). The delayed weight gain in bottlefed babies can be corrected or prevented by the addition of sodium bicarbonate to the milk. A pattern of delayed gain in weight has been described in premature infants who manifest late metabolic acidosis (Kilderberg, 1964). Sodium bicarbonate given by mouth produced a gain in weight as well as a correction of the acidosis. The full-term bottle-fed infants did not show signs of acidosis during the phase of growth lag. Nevertheless, they gained weight within 24 hours after the addition of alkali to feeds. Further investigations indicated that cow's milk was more acid than human breast milk.

This study was undertaken to determine the significance of these observations. It is concerned with the effects of a pHcorrected cow's milk on the early growth pattern of newborn infants and on the nature of their stool flora. The investigations were conducted on similar groups of breast-fed and bottle-fed babies.

\section{Material and Methods}

Breast Milk pH.-The $\mathrm{pH}$ was measured daily for seven days on the colostrum and milk of 92 lactating mothers. Milk was expressed directly into a sterile test tube at a fixed time each day. This was done before a feed. In 10 cases a second sample was collected under anaerobic conditions in a capillary tube. The ends were immediately sealed with wax. The $\mathrm{pH}$ was measured within five minutes by the Astrup technique, using a capillary electrode (Radiometer G297/G2).

Cow's Milk $p H$.- Twenty-four milks of varying strengths and makes were reconstituted with water $(\mathrm{pH} \mathrm{7 \cdot 80)}$ to a volume of $75 \mathrm{ml}$. They were then sterilized at $110^{\circ} \mathrm{C}$ at $15-\mathrm{lb}(6 \cdot 8-\mathrm{kg})$ pressure for 10 minutes and then refrigerated. Each feed was rewarmed to $38^{\circ} \mathrm{C}$ and the $\mathrm{pH}$ measurements were done in triplicate. These milks were prepared on five separate occasions for $\mathrm{pH}$ readings.

Milk Titration.-Titratable acidity was determined on all samples submitted for $\mathrm{pH}$ measurement. A 6-ml volume of

TABLE I-Birth Weight and Percentage of Birth Weight of 50 Breast-fed and 50 Bottle-fed Full-term Infants. Mean \pm S.D.

\begin{tabular}{|c|c|c|c|c|c|c|c|c|c|c|}
\hline & & & & \multirow{2}{*}{$\begin{array}{l}\text { Birth Weight } \\
\text { (in grammes) }\end{array}$} & \multicolumn{6}{|c|}{ Days after birth ( $\%$ of Birth Weight) } \\
\hline & & & & & 3 & 4 & 5 & 6 & 7 & 8 \\
\hline $\begin{array}{l}\text { Human breast } \\
\text { Cow's milk }\end{array}$ & $\ldots$ & 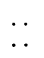 & $\ldots$ & $\begin{array}{l}3,394 \pm 352 \\
3,345 \pm 386\end{array}$ & $\begin{array}{l}97 \cdot 3 \pm 2 \cdot 1 \\
97 \cdot 9 \pm 2 \cdot 2\end{array}$ & $\begin{array}{l}98 \cdot 3 \pm 2 \cdot 5 \\
98 \cdot 5 \pm 2 \cdot 8\end{array}$ & $\begin{array}{l}99 \cdot 3 \pm 2 \cdot 7 \\
98 \cdot 9 \pm 3 \cdot 2\end{array}$ & $\begin{array}{r}100 \cdot 2 \pm 3.0 \\
99 \cdot 3 \pm 4 \cdot 1\end{array}$ & $\begin{array}{l}101.5 \pm 3.9 \\
100.0 \pm 4.5\end{array}$ & $100 \cdot \overline{9} \pm 4.7$ \\
\hline
\end{tabular}


sterile cow's milk and the same volume of fresh breast milk was titrated with $\mathbf{4 \cdot 2} \%$ sodium bicarbonate to a $\mathrm{pH}$ of $\mathbf{7 \cdot 4 0}$. End-point titration was determined on an automatic titrating unit (Radiometer ABU 11, TT 11, PMG 27). Titration was repeated by using the alkaline solution trometamol (Tham).

Viable E. coli Counts in Milk.-Bacteriological cultures were performed on 20 samples of reconstituted sterile cow's milk and 20 samples of fresh breast milk. A $6-\mathrm{ml}$ sample of milk was inoculated with about 2 by $10^{2}$ specific $E$. coli O111/B4 organisms. Viable counts were done on blood agar by the drop method (Miles et al., 1938) after 1, 3, 4, 6, and 7 huurs of incubation at $37^{\circ} \mathrm{C}$. All counts were done in triplicate. Similar cultures were repeated on titrated milk samples.

Infant Study.-The weights of 100 consecutive full-term infants were recorded for the first week of life. Fifty infants were breast-fed and 50 were bottle-fed. Their daily weight variations were expressed as a percentage of birth weight. The following small groups of infants were studied in detail: group 1, 10 normal full-term breast-fed babies; group 2, 10 normal bottle-fed infants; group 3,10 bottle-fed infants given sodium bicarbonate in feeds; and group 4, 10 bottle-fed babies given trometamol in feeds.

Weights. - The infants in each group were undressed and weighed at a fixed time each day before feeding. A dial scale (Salter model 40A) was used for this purpose.

Milk.-A humanized milk (Similac, Ross Laboratories) was given to all bottle-fed infants. The initial mean milk pH of 6.70 was raised to about $7 \cdot 20$ in groups 3 and 4 . This was done by adding $1 \mathrm{mEq}$ sodium bicarbonate to each feed of the infants in group 3, and $2 \mathrm{ml}$ trometamol to the feeds of infants in group 4. Infants received their particular feed within three hours of birth. Bottle-fed babies were offered a fixed volume of $100 \mathrm{ml}$ of milk. The amount ingested at each feed was noted and charted, and a strict intake and output chart was kept for each baby. The alkali additives were removed from the milks on the seventh day.

Acid Base and Serum Sodium.-Arterialized blood was collected from the heel of each bottle-fed infant on the fifth day of life. Acid base was measured immediately by using the Astrup technique. Serum sodium was determined on nonheparinized blood by flame photometry. Every attempt was made to avoid investigations not in the interest of the infant. Blood was not taken from the group of breast-fed babies. The nature of the study was explained to each mother and her consent obtained for all investigations.

Stools. - A fresh stool specimen was collected daily from each infant. The stool was placed in a clean plastic carton and taken immediately to the laboratory.

$\mathrm{pH}$ and Titration.-A $1-\mathrm{g}$ sample of stool was emulsified in $20 \mathrm{ml}$ normal saline. The $\mathrm{pH}$ of this solution was measured and it was then automatically titrated with $10 \mathrm{~N}$ lactic acid to a $\mathrm{pH}$ of 4.5.

Quantitative Bacterial Counts.-A fresh sample of stool weighing $0.10 \mathrm{~g}$ was emulsified with $100 \mathrm{ml}$ saline. Tenfold dilutions from $10^{-3}$ to $10^{-7}$ were prepared in normal saline. Bacterial counts were made from these dilutions on MacConkey and tomato juice agar plates by the drop method (Miles et al., 1938). E. coli organisms were counted on MacConkey plates after 24 hours' aerobic incubation at $37^{\circ} \mathrm{C}$. Lactobacilli were counted on tomato juice agar after 36 hours' anaerobic incubation at $37^{\circ} \mathrm{C}$ in $10 \%$ carbon dioxide. $E$. coli were identified as lactose fermenters on MacConkey's medium; lactobacilli were identified by colony appearance on tomato juice agar and by morphology on Gram stain. All investigations were subjected to statistical analysis, using the Kruskal Wallis one-way analysis of variance by ranks.

\section{Results}

MILK

pH and Titration.-Human breast milk had a mean pH of 7.29 (S.D. $\pm 0 \cdot 19$ ) with the range $6 \cdot 80-7 \cdot 70$ for the week after birth. Little daily variation occurred, and no difference was observed in the $\mathrm{pH}$ of milk collected under anaerobic conditions. The milk required an average of $0.07 \mathrm{mEq}$ (S.D. \pm 0.04 ) sodium bicarbonate for titration. Reconstituted cow's milk had a mean

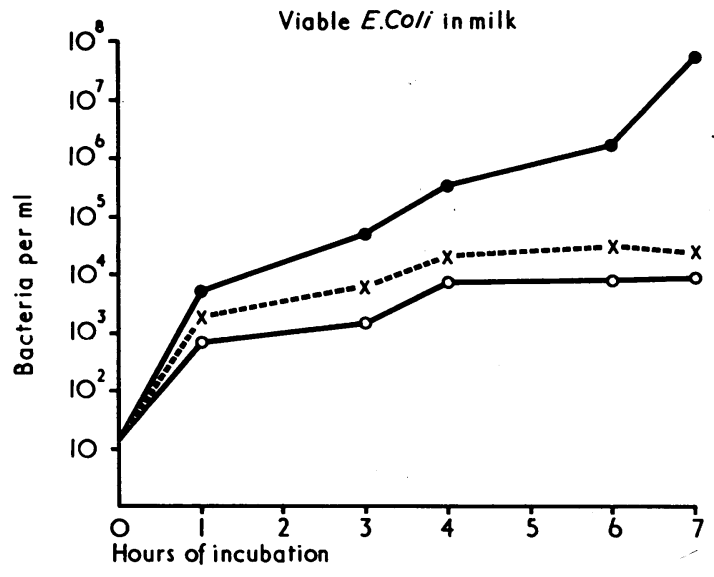

Specific $E$. coli 0111/B4 counts in milk during seven hours of incubation. $\mathrm{O}=$ Breast milk. $=$ Cow's milk. $\mathrm{X}=$ Cow's milk with alkali (bicarbonate and trometamol).

TABLE II-Specific E. coli 0111/B4 Counts in Milk. Mean \pm S.D.

\begin{tabular}{|c|c|c|c|c|c|}
\hline & \multicolumn{5}{|c|}{ Incubation Period (Organisms/ml) } \\
\hline & 1 Hour & 3 Hours & 4 Hours & 6 Hours & 7 Hours \\
\hline $\begin{array}{l}\text { Human breast } \quad \ldots \\
\text { Cow's milk } \ldots \\
\text { Cow's milk }+ \text { bicarbonate } \ldots \\
\text { Cow's milk }+ \text { trometamol } \ldots\end{array}$ & $\begin{array}{l}8 \times 10^{2} \pm 1 \times 10^{2} \\
7 \times 10^{2} \pm 1.2 \times 10^{3} \\
3.3 \times 10^{3} \pm 1.6 \times 10^{3} \\
2.5 \times 10^{2} \pm 1.0 \times 10^{2}\end{array}$ & $\begin{array}{l}2 \times 10^{2} \pm 4 \times 10^{2} \\
7 \times 10^{4} \pm 2.4 \times 10^{4} \\
7.6 \times 10^{3} \pm 1.4 \times 10^{3} \\
7.6 \times 10^{3} \pm 2.0 \times 10^{3}\end{array}$ & $\begin{array}{l}9 \times 10^{3} \pm 2 \times 10^{3} \\
5 \times 10^{5} \pm 2.4 \times 10^{5} \\
1.4 \times 10^{4} \pm 7.1 \times 10^{3} \\
1.7 \times 10^{4} \pm 9.0 \times 10^{3}\end{array}$ & $\begin{array}{l}9 \times 10^{3} \pm 1.3 \times 10^{2} \\
6 \times 10^{4} \pm 2.6 \times 10^{6} \\
1.9 \times 10^{4} \pm 8.3 \times 10^{3} \\
3.2 \times 10^{4} \pm 9.0 \times 10^{3}\end{array}$ & $\begin{array}{l}8 \times 10^{3} \pm 1.2 \times 10^{3} \\
6.6 \times 10^{7} \pm 3 \times 10^{7} \\
1.8 \times 10^{4} \pm 8.6 \times 10^{3} \\
2.8 \times 10^{4} \pm 8.8 \times 10^{3}\end{array}$ \\
\hline
\end{tabular}

Bacterial growth (three to seven hours' incubation) in unaltered cow's milk differs significantly $(P<0.0005)$ from that in human breast milk or cow's milk with alkali additives.

TABLE III-Gestation and Weights of the 40 Infants in the Study Groups. Mean \pm S.D.

\begin{tabular}{|c|c|c|c|c|c|c|c|c|c|c|}
\hline \multirow{2}{*}{ Group } & \multirow{2}{*}{$\begin{array}{l}\text { Gestation } \\
\text { ('Weeks) }\end{array}$} & \multirow{2}{*}{$\begin{array}{l}\text { Birth Weight } \\
\text { (in grammes) }\end{array}$} & \multicolumn{8}{|c|}{ Days after Birth (Weight in Grammes) } \\
\hline & & & 3 & 4 & 5 & 6 & 7 & 8 & 9 & 10 \\
\hline $\begin{array}{l}1 \\
2 \\
3 \\
4\end{array}$ & $\begin{array}{l}40.0 \pm 0.4 \\
39.7 \pm 0.7 \\
40.0 \pm 0.8 \\
40.0 \pm 0.3\end{array}$ & $\begin{array}{l}3,158 \pm 475 \\
3,144 \pm 356 \\
3,176 \pm 372 \\
3,244 \pm 394\end{array}$ & $\begin{array}{l}3,044 \pm 464 \\
3,083 \pm 386 \\
3,120 \pm 381 \\
3,144 \pm 365\end{array}$ & $\begin{array}{l}3,057 \pm 407 \\
3,087 \pm 371 \\
3,155 \pm 359 \\
3,187 \pm 394\end{array}$ & $\begin{array}{l}3,115 \pm 403 \\
3,090 \pm 382 \\
3,192 \pm 365 \\
3,208 \pm 360\end{array}$ & $\begin{array}{l}3,161 \pm 425 \\
3,088 \pm 409 \\
3,230 \pm 368 \\
3,208 \pm 378\end{array}$ & $\begin{array}{l}3,196 \pm 405 \\
3,125 \pm 396 \\
3,246 \pm 368 \\
3,245 \pm 405\end{array}$ & $\begin{array}{l}3,140 \pm 377 \\
3,113 \pm 331 \\
3,230 \pm 454\end{array}$ & $\begin{array}{c}3,171 \pm 374 \\
3,194 \pm 383 \\
3,277 \pm 370\end{array}$ & $\begin{array}{l}3,185 \pm 382 \\
3,211 \pm 354 \\
3,307 \pm 390\end{array}$ \\
\hline
\end{tabular}

Group 1, Breast fed (10 infants). Group 2, Bottle fed (10 infants). Group 3, Bicarbonate added to milk for seven days (10 infants). Group 4, trometamol added to milk for seven days (10 infants). 
pH of 6.51 with a range from 5.60 to 6.95 depending on the particular brand and its dilution. A larger amount of sodium bicarbonate (average $0.64 \mathrm{mEq}$ ) was necessary for end-point titration.

Viable E. coli Counts.-Breast milk remained relatively bacteriostatic over a seven-hour period (see Chart). E. coli counts averaged $8 \times 10^{2}$ organisms $/ \mathrm{ml}$ at one hour and thereafter the mean count did not exceed $9 \times 10^{3}$ (Table II). Reconstituted cow's milk averaged $7 \times 10^{3}$ organisms $/ \mathrm{ml}$ at one hour and a mean $6.6 \times 10^{7}$ at seven hours. Once alkali had been added to the milk the growth of bacteria was discouraged. Milks with sodium bicarbonate averaged $E$. coli counts of $3.3 \times 10^{3}$ at one hour and reached a mean of $1.8 \times 10^{4}$ at seven hours. Those with trometamol ranged from a mean $2.5 \times 10^{3}$ (one hour) to $2.8 \times 10^{4}$ at seven hours (Table II).

\section{INFANTS}

Weights.-Breast-fed babies lost a mean $2.7 \%$ of their birth weight by day 3 (Table $\mathrm{I}$ ) and regained this weight $5 \cdot 7$ days after birth. Bottle-fed babies had an average weight loss of $2 \%$ and reached birth weight at a mean seven days of age. Weight differences in each group were not statistically significant, but the time taken to regain birth weight showed a significant variation between these groups $(P>0.05)$. Similar weight patterns were seen in all groups and all had comparable weights and gestational ages (Table III). Breast-fed infants (group 1) had regained birth weight by 5.9 days of age, whereas bottle-fed infants (group 2) reached this weight at a mean 8.7 days of age. Infants fed an alkali (groups 3 and 4 ) had a weight pattern which resembled that in group 1 . Those on bicarbonate (group 3 ) had regained birth weight by 5 days of age, while the trometamol group (group 4) regained this weight at a mean seven days after birth. In group 3, growth remained steady until 24 hours after the removal of alkali. At this stage (eighth day of life) a mean weight loss of $2 \%$ occurred, and thereafter weight increased up to the tenth day of age. Group 4 infants showed less striking growth arrest after the removal of alkali from the milk. Weight differences among these small groups were not statistically significant. The time taken to regain birth weight showed a significant difference in groups 1 and 2 , and in groups 2 and 3 $(P>0.05)$

Fluids.-Adequate fluid intake was recorded in all bottle-fed infants for the first seven days of life. Those not receiving alkali averaged $512 \mathrm{ml}$ a day $(162 \mathrm{ml} / \mathrm{kg}$ birth weight) while the bicarbonate group ingested a mean $488 \mathrm{ml}$ a day $(153 \mathrm{ml} / \mathrm{kg}$ birth weight), and the trometamol group received a mean $539 \mathrm{ml}$ a day ( $165 \mathrm{ml} / \mathrm{kg}$ birth weight).

Acid Base and Serum Sodium.-Normal acid base values were present in all bottle-fed babies. Those in group 2 had a mean pH of 7.40 (S.D. \pm 0.02 ), a $\mathrm{PCO}_{2}$ of $41.0 \mathrm{~mm} \mathrm{Hg}$ (S.D. \pm 3.0 ), and a base excess of $+0.7 \mathrm{mEq}$. The values for group 3 were: mean pH 7.40 (S.D. \pm 0.02 ), $\mathrm{PCO}_{2} 43.7 \mathrm{~mm} \mathrm{Hg}$ (S.D. \pm 3.5 ), base excess $+2.0 \mathrm{mEq}$; and for group 4 the values were: mean pH 7.40 (S.D. \pm 0.02 ), $\mathrm{PCO}_{2} 42 \cdot 2 \mathrm{~mm} \mathrm{Hg}$ (S.D. $\pm 2 \cdot 7$ ), and base excess $+1 \cdot 1 \mathrm{mEq}$. Serum sodium averaged $141 \mathrm{mEq} / \mathrm{l}$.
(S.D. $\pm 2 \cdot 8$ ) in group $2,142 \mathrm{mEq} / 1 .($ S.D. \pm 5.0$)$ in group 3, and $140 \mathrm{mEq} / \mathrm{l}$. (S.D. \pm 4.8 ) in group 4 .

STOOLS

$p H$ and Titration.-The stools from infants in group 1 had a mean $\mathrm{pH}$ of 5.2 for the first week of life (Table IV). They required a mean $0.06 \mathrm{ml}$ acid for titration to $\mathrm{pH} 4.5$. Stools from infants in group 2 had a mean $\mathrm{pH}$ of 5.9 with an average titratable alkalinity of $0.30 \mathrm{ml}$. Those from infants in group 3 had

TABLE IV-Stool pH and Titratable Alkalinity (10N Lactic Acid) in the 40 Infants in the Study Groups. Mean \pm S.D.

\begin{tabular}{|c|c|c|c|c|}
\hline \multirow{3}{*}{ Group } & \multicolumn{4}{|c|}{ Days After Birth } \\
\hline & \multicolumn{2}{|c|}{ Days 2-7 } & \multicolumn{2}{|c|}{ Days 8-10 } \\
\hline & $\mathrm{pH}$ & Acid (ml) & $\mathrm{pH}$ & Acid (ml) \\
\hline \multirow[t]{2}{*}{$\begin{array}{l}1 \\
2 \\
3 \\
4\end{array}$} & $\begin{array}{l}5.2 \pm 0.4 \\
5.9 \pm 0.3 \\
5.5 \pm 0.4 \\
5.4 \pm 0.4\end{array}$ & $\begin{array}{l}0.06 \pm 0.03 \\
0.30 \pm 0.17 \\
0.18 \pm 0.20 \\
0.12 \pm 0.17\end{array}$ & $\begin{array}{l}6.0 \pm 0.3 \\
6 \cdot 2 \pm 0.4 \\
6.2 \pm 0.4\end{array}$ & $\begin{array}{ll}0.40 & \pm 0.24 \\
0.46 & \pm .20 \\
0.56 \pm 0.40\end{array}$ \\
\hline & \multicolumn{2}{|c|}{$\begin{array}{l}\text { Group } 2 \text { differs from others, } \\
\qquad \mathrm{P}<0.0005\end{array}$} & \multicolumn{2}{|c|}{ Groups 2,3 , and $4, P>0.1$} \\
\hline
\end{tabular}

an average $\mathrm{pH}$ of 5.5 and titratable alkalinity of $0.18 \mathrm{ml}$ up to day 7. Once bicarbonate was stopped $\mathrm{pH}$ increased to an average 6.2 for the remaining three days. The amount of acid needed for titration rose to a mean $0.46 \mathrm{ml}$. Infants in group 4 showed a similar pattern. The mean stool $\mathrm{pH}$ up to day 7 was 5.4 with a titratable alkalinity of $0.12 \mathrm{ml}$. After the removal of trometamol from the milk $\mathrm{pH}$ increased to a mean 6.2 and titratable alkalinity to $0.56 \mathrm{ml}$.

Cultures. - Stools from infants in group 1 had an average $E$. coli count of $2 \times 10^{8}$ and a lactobacilli count of $2 \times 10^{10}$ organisms per gramme for the first week (Table V). Stools from infants in group 2 showed a reversal of this pattern. E. coli counts averaged $5.4 \times 10^{10}$ and lactobacilli counts $5.4 \times 10^{9}$. The addition of alkali to the milk promoted colonization of the bowel with organisms similar to those in breast milk stools. In group 3 the mean $E$. coli count for the first week was $7.2 \times 10^{9}$. This rapidly increased to a mean of $4.8 \times 10^{11}$ over the next three days, after the removal of bicarbonate. Mean lactobacilli counts before and after the removal of bicarbonate were $6.4 \times 10^{11}$ and $5.3 \times 10^{9}$ respectively. Stools from infants in group 4 averaged $E$. coli counts of $3.2 \times 10^{8}$ and lactobacilli counts of $1.3 \times 10^{10} / \mathrm{g}$ for the first seven days. Once trometamol had been removed these counts were reversed. $E$. coli counts now averaged $6.4 \times 10^{10} / \mathrm{g}$, while the lactobacilli count was a mean $2 \times 10^{8}$.

\section{Discussion}

Titration of cow's milk with alkali to a $\mathrm{pH}$ of $7 \cdot 20-7 \cdot 40$ has several striking consequences. The altered milk has a bacteriostatic effect on specific $E$. coli in vitro; it promotes early growth

TABLE v-Stool E. coli and Lactobacilli Counts and Range in the 40 Infants in the Study Groups

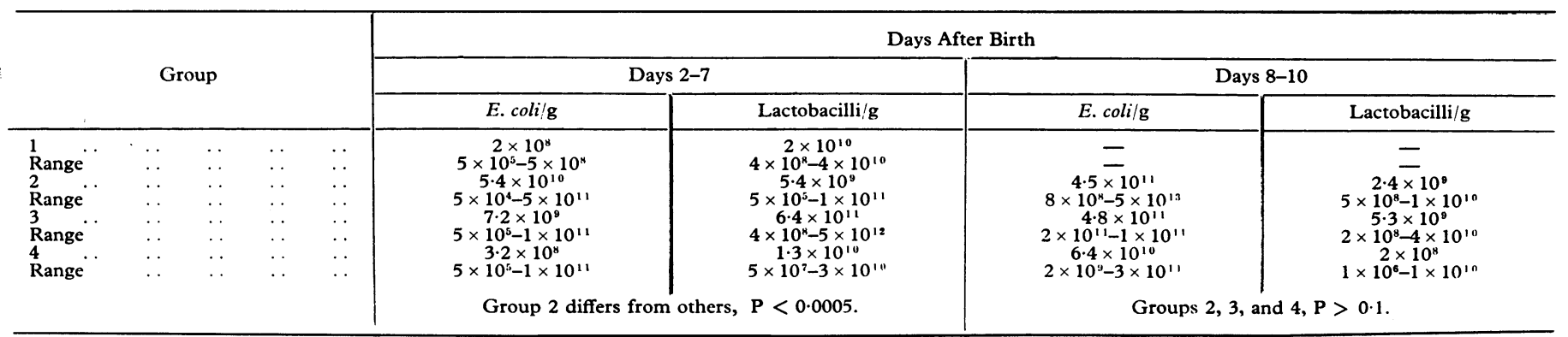


in the newborn baby, and alters the $\mathrm{pH}$ and microflora of the infant's stool. The changes appear to simulate those produced by human milk.

Human milk and bovine colostrum are known to have a bacteriostatic effect on specific $E$. coli in the $\mathrm{pH}$ range of $7 \cdot 20$ 7.33 (Bullen et al., 1972). A similar effect was observed in reconstituted cow's milk ( $\mathrm{pH} 7 \cdot 40$ ), but the reason for this inhibition is unknown. Bullen et al. (1972) indicated that the bacteriostatic effect could be enhanced by iron-binding proteins provided the $\mathrm{pH}$ is maintained above $7 \cdot 0$. They thought that the alkaline condition of the small bowel would be suitable for the inhibition of $E$. coli, particularly if milk reached this region in an undigested state. In support of this theory they noted the works of Mason (1962), who showed that stomach $\mathrm{pH}$ does not fall to a stage at which casein hydrolysis can occur, and Henderson (1942), who pointed out that milk passes rapidly into the newborn's duodenum during feeding. It is likely that in these circumstances the bacteriostatic effect of titrated cow's milk shown in vitro may continue to function in the small bowel.

The bacteriostatic property of titrated milk may be of practical significance in infant feeding. Milk formulas easily become contaminated with bacteria when terminal sterilization is not practised. This hazard is most pronounced in the homes of low socioeconomic groups, where up to $50 \%$ of feeds show contamination with enteric organisms. When such feeds are prepared in bulk and stored for more than 24 hours contamination by $E$. coli can be as high as $38 \%$ (Kendall et al., 1971).

The stool flora of infants on titrated cow's milk resembled that of breast-fed babies. Bullen and Willis (1971) indicated that while $E$. coli counts were low in breast-fed infants and lactobacilli counts were high, the situation was reversed in bottle-fed babies. In the present study $E$. coli counts remained below $10^{10}$ per gramme while infants were fed on titrated milk. A significant increase of $E$. coli organisms was noted once alkali had been removed from the feeds. $E$. coli counts in the stools now approached those of infants on unaltered cow's milk. Stool lactobacilli counts were inversely related to the $E$. coli counts.

Stools of infants on alkali resembled those of breast-fed babies in that they were equally acid and had a reduced buffering capacity. Ross and Dawes (1954) thought that the preponderance of lactobacilli in the bowels of breast-fed babies and the relatively low $\mathrm{pH}$ were major factors responsible for resistance to gastroenteritis. It is likely that titrated cow's milk leading to a stool with a high lactobacillus count and low $\mathrm{pH}$ could provide similar resistance for the bottle-fed baby.

The growth promoting effect of titrated cow's milk was similar to that of breast milk. Consistent early weight gain of infants on sodium bicarbonate could not be attributed to fluid retention or to an increased intake of calories. Serum sodium levels were normal. The humanized cow's milk had a sodium content of $11 \mathrm{mEq} / \mathrm{l}$, and the maximum daily intake of sodium by infants in the trial was estimated at $12 \mathrm{mEq}$. No recommendation can be given for the addition of sodium bicarbonate to milks containing a higher content of sodium. This compares favourably with the calculated maximum amount of $13 \mathrm{mEq}$ a day for infants on unaltered cow's milk. Weight gain was not specific for sodium bicarbonate as infants receiving the electrolytefree trometamol solution showed a similar weight and stool pattern.

A major point of consideration in the weight gain concerns the effect of bowel flora on the host. In this study a striking relation was noted between the numbers of $E$. coli in stool cultures and the growth pattern. During the stages of weight lag large numbers of $E$. coli were present in the stools. Intestinal flora are known to affect growth in health and disease. They play a major part in conditions such as the blind loop syndrome (Brown, 1969), megaloblastic anaemia (Foy et al., 1951), and kwashiorkor (Smythe, 1958). In healthy infants (Robinson, 1952) and in animals growth promotion has been achieved by an alteration of the bowel flora with antibiotics. Piglets fed a diet containing sulphonamides showed improved daily weight gain. Their stools had a reduced $E$. coli count during the period of weight gain whereas lactobacilli remained unaffected (Wahlstrom et al. 1950). It has been postulated that the increase in growth produced by antibiotics could be due to the destruction of bacteria which compete with the host for foodstuffs, to an increase in growth factors produced by bacteria, or to the elimination of toxic compounds released by bacteria (Stokstad, 1954). Titrated milk may act in a similar way by preventing the overgrowth of $E$. coli organisms which could compete with the host for nutrition.

The growth lag noted in infants on unaltered cow's milk could not be attributed to an associated metabolic acidosis. To a certain extent the pattern resembled that described by Kilderberg (1964) in premature infants. He specifically noted that weight lag preceded metabolic acidosis, and it is feasible that the acidosis was due to the excessive acid load in artificial cow's milk. The growth achieved by his group of immature infants on sodium bicarbonate may have been due to an alteration of bowel flora rather than to the correction of metabolic acidosis per se.

Milk which has been titrated with alkali appears to be a more physiological food for the newborn infant than unaltered cow's milk.

This study was confined to correcting milk acidity by the addition of sodium bicarbonate or trometamol. The alkali was given for a short period only, and may be contraindicated for long-term use. The question whether it is more feasible to remove the acid radicals from cow's milk or to titrate the milk with alkali has not been examined.

We wish to thank Sr. M. Charles for collections of milk, Drs. C. Watson and A. Naude for bacteriological advice, Dr. M. Berger for serum sodium estimations, and Dr. A. Falconer, medical superintendent of Mowbray Maternity Hospital, for permission to report patient records.

The study was supported by a grant from the Harry Crossley Foundation, Cape Town.

\section{References}

Brown, A. (1949). British Medical fournal, 1, 1073.

Bullen, C., and Willis, A. (1971). British Medical fournal, 3, 338.

Bullen, J., Rogers, H., and Leigh, L. (1972). British Medical fournal, 1, 69. Foy, H., Kondi, A., and Hargreaves, A. (1951). British Medical fournal, $1,380$.

Henderson, S. (1942). American fournal of Roentgenology, Radium Therapy, and Nuclear Medicine, 48, 302.
anderican fourno

Kendall, N., Vaughan, V., and Kusakcioglu, A. (1971). American fournal of Diseases of Children, 122, 215.

Kilderberg, P. (1964). Acta Paediatrica Scandinavica, 53, 517.

Mason, S. (1962). Archives of Disease in Childhood, 37, 387.

Miles, A., Misra, S., and Irwin, J. (1938). Fournal of Hygiene, 38, 732.

Robinson, P. (1952). Lancet, 1, 52.

Ross, C., and Dawes, E. (1954). Lancet, 1, 994.

Smythe, P. (1958). Lancet, 2, 724.

Stokstad, E. (1954). Physiological Reviews, 34, 25.

Wahlstrom, R., Terrill, S., and Johnson; B. (1950). Proceedings of the Society for Experimental Biology and Medicine, 75, 710. 